\title{
Esperança que nasce da experiência e nutre o cotidiano
}

Rosemary Fernandes da Costa

A esperança ainda está presente no coração das pessoas? Em tempos de mudanças sociais, políticas, religiosas, há ainda espaço para a esperança? Há uma experiência religiosa que alimente e potencialize a esperança? Há uma relação entre a fé e a esperança?

Nesta pequena reflexão trabalharemos com o tema da ESPERANÇA. Poderíamos aqui abordar a questão do sentido da vida, trazer debates filosóficos e teológicos, mas faremos um caminho diferente, voltando nossa atenção para a estética, especialmente para o que a música popular brasileira pode nos oferecer para esta reflexão.

Seguiremos um percurso através de algumas músicas populares brasileiras, observando nestas composições indicativos de como nosso povo compreende a busca por dias melhores e, ao mesmo tempo, constrói sua história enraizados nesta esperança.

Para nos auxiliar nesta reflexão, propomos um breve passeio pelos caminhos que o povo brasileiro vem trilhando na busca pelo sentido da vida, através de três chaves de leitura: a esperança, o cotidiano e a proximidade de Deus.

Compreendendo a teologia como tarefa comunitária, trazemos aqui um pouco das vozes de nossa cultura, cantada, dançada, permeada de metáforas que apontam para significados profundos e fecundantes de uma história de esperança para os povos, para a terra e toda a criação.

\section{A esperanca alinhavando passado, presente e futuro}

A experiência humana que articula passado, presente e futuro é o próprio dinamismo do ser humano em sua busca de sentido, de revisão e de novas escolhas. O tempo presente é recheado de avaliações, construções e desconstruções, de novos fazeres, a fim de criar um novo ânimo para que o agora seja sinal de realização e de vida nova. Neste dinamismo apresentamos a composição Tocando em Frente, de Almir Sater e Renato Teixeira'. Observemos seu percurso reflexivo. ${ }^{2}$

Ando devagar porque já tive pressa e levo esse sorriso, porque já chorei demais Hoje me sinto mais forte, mais feliz quem sabe

eu só levo a certeza de que muito pouco eu sei, eu nada sei

Conhecer as manhas e as manhãs, o sabor das massas e das maçãs,

é preciso o amor pra poder pulsar, é preciso paz pra poder sorrir,

é preciso a chuva para florir(...)

\footnotetext{
${ }^{1}$ A toada Tocando em Frente é uma composição de Almir Sater e Renato Teixeira, gravada em 1980. Segundo os compositores a música parece ter sido uma inspiração espiritual, já que foi composta em um espaço de tempo mínimo, em 10 minutos. Os autores declararam: "Ela estava pronta... Deus apenas esperou que eu e o Renato nos encontrássemos para mostrá-la pra gente". Disponível em http://mais.uol.com.br/view/e9k2j91iyhc9/tocando-emfrente--almir-sater--renato-teixeira-04029A316ED49123A6?types=A\&.

${ }^{2}$ As canções apresentadas neste trabalho para nossa reflexão serão pontuadas em apenas alguns de seus versos. Para uma análise mais detalhada de cada composição sugerimos os links apontados nas notas.
} 
Nesta composição estão presentes o olhar retrospectivo, a compreensão de que o passado inspira e fundamenta o presente e o futuro; a simplicidade e humildade de reconhecer o horizonte aberto ao futuro e, ao mesmo tempo, os fundamentos que podem qualificar o momento presente.

Esta composição nos remete à experiência do cotidiano do boiadeiro, a observação contemplativa e hermenêutica que integra história e esperança. $\mathrm{E}$ ainda podemos perceber a compreensão do dinamismo pessoa-comunidade e o impulso maior da história e da vida humana para a felicidade. O desejo por uma realidade transformada, onde reina o bem e a justiça está presente, mas ainda não plenamente. Contudo, é uma presença que permite falar da certeza-esperança da realização plena.

Quem encontra inspiração no olhar nordestino é também Caetano Veloso, com a belíssima Cajuína ${ }^{3}$. Observemos com atenção seu movimento poético e contemplativo.

Qual será o destino de nosso existir? Caetano Veloso aponta para algo mais profundo, que encontra como matéria prima e latente no ser humano. É como encontrar a fonte de uma vida nova em meio à dor que o presente parece imprimir ao olhar do menino. A fonte é cristalina. É ela que potencializa o futuro e aponta para a esperança. A fé caminha por este exercício de decifrar o sentido radical dentro da vida cotidiana. É dizer que o ser humano tem um futuro garantido pelo amor radical e para este futuro convergimos com nossos encontros e desencontros.

Existirmos a que será que se destina

Pois quando tu me deste a rosa pequenina

Vi que és um homem lindo e que se acaso a sina

De um menino infeliz não se nos ilumina (...)

Um segundo trabalho que revela a perspectiva de um mundo melhor e a orientação para essa conquista através do agir cotidiano é uma das muitas composições de Ronaldo Bastos e Beto Guedes. Trata-se da obra Sal da Terra ${ }^{4}$, bem conhecida mas, vejamos mais uma vez, agora com o olhar permeado por esta reflexão.

Desde o primeiro verso, a canção fala de algo conhecido mas do qual nem sempre temos consciência: de que a casa é de todos, é casa comum e, portanto, é responsabilidade de cada um. Segue trazendo uma dobradinha: diagnósticos e orientações éticas. Essas orientações não são mandatos, mas caminhos de felicidade para todos, princípios que brotam de dentro para fora, da atitude de amor a tudo que vive e de diálogo fraterno. A dimensão do

\footnotetext{
${ }^{3}$ A canção Cajuína, de Caetano Veloso, foi gravada em 1979. É um baião metafísico que levanta a indagação essencial do homem neste mundo. Foi composta por causa de seu tio Heli. Caetano havia chegado a Teresina para um show, estava muito triste, devido ao suicídio de seu grande amigo e parceiro musical, o poeta Torquato Neto. Caetano procurou tio Heli, pai de Torquato. Este levou Caetano para casa, serviu-lhe uma cajuína, e procurou consolá-lo, pois Caetano chorava muito, convulsivamente. Em determinado instante, tio Heli saiu da sala e foi ao jardim, onde colheu uma rosa-menina, e deu a Caetano. Ali mesmo os versos de Cajuína começaram a surgir. Disponível em http://colocandoospaposemdia.blogspot. com/2010/09/caetano-veloso-cajuina.html.

${ }^{4}$ A canção foi composta em 1981, pelo mineiro de Montes Claros, Beto Guedes e o fluminense de Niterói, Ronaldo Bastos.
} 
Reino está aí presente, com seus sinais de 'já' e de 'ainda não', com a certeza da vida nova que já é construída no presente e garantida no futuro. A chave da canção - o sal da terra - é categoria da Boa Nova anunciada e presente em todo ser humano aberto ao dinamismo de Graça de Deus.

(...) Vamos precisar de todo mundo. Um mais um é sempre mais que dois

Pra melhor juntar as nossas forças é só repartir melhor o pão

Recriar o paraíso agora para merecer quem vem depois

Deixa nascer o amor, deixar florir o amor, deixa crescer o amor, deixa viver o amor, o Sal da terra.

Observemos como todas as dimensões estão integradas nesta composição: o planeta, o ser humano, a sociedade, o passado, o presente, o futuro, a paz, a justiça, a história, o amor, o pão, a maçã. E o verbo final revela também brilhante percepção - 'deixa' - porque já está tudo aí, aguardando amorosamente a liberdade e a disponibilidade de cada um para acontecer.

Ronaldo Bastos e Beto Guedes trabalham movendo significados muito marcados pela esperança fundada no amor, no cuidado, no bem comum. As dimensões de fé, esperança e amor dançam pela linguagem poética convidando o ouvinte a aceitar o convite e modificar seu pensar e seu agir.

\section{A fé que potencializa os passos cotidianos}

Palavra com múltiplos significados, a fé está sempre presente como fundamento, apoio e motivação para o ser humano. Mesmo que não entremos no ponto de vista religioso, sem fé não se caminha, como diz a canção de Gilberto Gil, Andar com Fé5.

Andar com fé eu vou, que a fé não costuma faiá

Que a fé tá na mulher, a fé tá na cobra coral, num pedaço de pão

A fé tá na maré, na lâmina de um punhal, na luz, na escuridão (...)

Gilberto Gil convida a olharmos a fé como fundamento do caminhar. Sem fé, não há sentido, portanto, não há razão para existir, não há sentido no cotidiano e nem no futuro, não há ligação entre as situações, pessoas, histórias, mundo. A fé insiste, persiste, encontra brechas, novos caminhos.

Como vimos na canção anterior - Sal da Terra - aqui há também uma abordagem plural, multidimensional, complexa. Gilberto Gil não escolhe lados, e sim amplia o olhar para além do bem e do mal, do certo e do errado. Ele fala da fé como grande aposta e movimento. Ter fé já é caminhar, já é acreditar que vai dar certo, já é esperar um amanhã melhor do que o hoje.

\footnotetext{
${ }^{5}$ Gilberto Gil compôs esta música em 1982. Uma das curiosidades desta canção é o uso da expressão 'faiá' em vez da linguisticamente correta "falhar". Gil explica a utilização desse recurso: "O uso do 'faiá' é uma homenagem ao linguajar caipira, ao modo popular mineiro, paulista, baiano - brasileiro. É quase como se a frase na canção não pudesse ser verdade se 0 verbo fosse pronunciado corretamente. Disponível em http://musicaemprosa.musicblog.com.br/262500/Gilberto-Gil-Andar-com-fe.
} 
Mas ainda falando da fé que dispõe o ser humano no dinamismo do projeto de Deus, do acontecer de Deus na resposta humana, do acontecer humano no sim à Graça que tudo permeia e abraça, trazemos a composição de Herbert Vianna, O Soldado da Paz ${ }^{6}$.

Não há perigo que vá nos parar

Se o bom de viver é estar vivo, ter amor, ter abrigo

Ter sonhos, ter motivos pra cantar (...)

Aqui temos uma linguagem que fundamenta a esperança no agir cotidiano, um agir comprometido com a vida, com a paz, mas que não é simples: dá motivos para cantar, mas também motivos para lutar. O tema do sacrifício da vida em direção às metas desejadas nos faz pensar em duas dimensões da esperança humana: a orientação vital e a dimensão comunitária. A esperança não é apenas pessoal, é compartilhada, é sonho de todos e luta de todos. A realização, portanto, é compromisso concreto que exige que cada um se envolva, construa estratégias históricas, reveja seus propósitos na direção do sonho comum.

O discernimento ético alinhava toda a canção e fala de maturidade. Traz o dado concreto e histórico de saber fazer a escolha que conduza à vida e não à morte, que conduza ao amor e não à guerra. $\mathbf{O}$ sim da esperança não se confunde com outras afirmações que conduzem à injustiça, à desigualdade, à ausência de direitos humanos. O último verso reúne esforço vital, sacrifício e construção histórica - "quanto mais se sacrifica a vida, mais a vida e o tempo são os seus aliados". Afirmação fundamental em muitas experiências religiosas, inclusive no Cristianismo: semear a terra é fazer brotar a vida verdadeira para tudo e todos.

E, por falar nisso, trazemos mais uma composição de Gilberto Gil, cheia de idas e vindas pela história pessoal, comunitária e ambiental: Drão ${ }^{7}$.

Drão, o amor da gente é como um grão, uma semente de ilusão, tem que morrer pra germinar, plantar n'algum lugar, ressuscitar no chão nossa semeadura

Quem poderá fazer, aquele amor morrer, nossa caminha dura

Dura caminhada, pela estrada escura(...)

A composição de Gilberto Gil é uma verdadeira oração que reúne humildade, entrega, pedido de perdão, oferta da vida, esperança pascal. Toda vida é iluminada pela crença de que a vida não é vã, é assumida pelo amor que tem a palavra final, e a palavra é de pão, que alimenta e partilha. Um Deus vivo, presente e misericordioso vem ao encontro de cada grão semeado.

Como na canção anterior, de Toni Garrido, esta também tem um chão marcado pelos erros e acertos, pela certeza do caminhar nem sempre iluminado, mas certo do amor

\footnotetext{
${ }^{6}$ Soldado da Paz é uma composição de Herbert Vianna, gravada pela banda em 2000 no álbum "Enquanto o Mundo Gira" foi cedida ao grupo Cidade Negra para gravação.

7 A canção de Gilberto Gil foi gravada em 1982. Drão é uma referência à sua esposa Sandra, apelidada dessa forma por Maria Bethânia. O casal estava se separando e Gil fala de um amor que se transforma e se eterniza. Gilberto Gil explica que esta foi uma canção muito trabalhada, demorou muitos dias e noites escrevendo seus versos e elaborando a criação que brotava. Disponível em http://www.gilbertogil.com.br/sec_musica.php?page=2.
} 
compassivo que orienta os grãos a ser tornarem. Aqui também é preciso morrer para nascer trigo, a semeadura é histórica, concreta, cotidiana. A oferta da vida é possibilidade de participar da partilha final. A fé não se compreende apenas no âmbito pessoal, e entra no dinamismo vivificante e transformador que converte a história. Aqui também se tecem passado, presente e futuro no horizonte da esperança por dias melhores.

\section{A certeza-esperanca que faz celebrar a vida desde já}

Se a fé é cotidiana e é caminho na esperança, é também impulso para a festa, a alegria, a celebração das utopias humanas, históricas, cósmicas. Neste tema é tarefa impossível selecionar composições de nosso povo, pois este é o cantar mais frequente no chão brasileiro. Uma dentre as muitas canções que poderiam nos conduzir por este tema é a Amanhã , de Guilherme Arantes ${ }^{8}$.

(...)Amanhã a luminosidade alheia a qualquer vontade há de imperar Amanhã está toda a esperança, por menor que pareça existe e é pra vicejar (...)

A certeza-esperança move o compositor e seu poema-canção. Ele descobre o dinamismo da vida e confirma que tudo é mediação para o Absoluto amoroso que, embora não alcançado em sua plenitude, já anuncia a festa final. O poema revela o mistério que se aninha no fundo de cada ser humano, de cada passo cotidiano, que une o existencial e o cosmos.

Ressalta a dimensão cósmica do primeiro ao último verso. Ajoelha-se diante do mistério e abre os braços para o louvor, a gratidão, a reconciliação. O fim da estrada é de sol, ódios aplacados, temores abrandados, amor que supera toda resistência. É a grande integração de tudo e todos, tematizando a trama da existência e apostando na comunhão perfeita.

Para concluir não podemos deixar de refletir sobre a belíssima composição de Luiz Carlos da Vila, Por um dia de graça. A esperança latente em cada verso gera o sorriso, a certeza em cada palma de mão, em cada palmo de chão, a luta cotidiana do povo tornada semeadura do novo tempo de graça.

\footnotetext{
Um dia, meus olhos ainda hão de ver na luz do olhar do amanhecer sorrir o dia de graça

Poesias, brindando essa manhã feliz, do mal cortado na raiz, do jeito que o mestre sonhava

O não chorar e o não sofrer se alastrando, no céu da vida o amor brilhando,

A paz reinando em santa paz

Em cada palma de mão, cada palmo de chão, semente de felicidade

O fim de toda a opressão, o cantar com emoção, raiou a liberdade

Chegou o áureo tempo de justiça, ao esplendor do preservar a natureza,

Respeito a todos os artistas.

A porta aberta ao irmão, de qualquer canto e qualquer raça

O povo todo em louvação por esse dia de graça!
}

\footnotetext{
${ }^{8}$ Guilherme Arantes compôs Amanhã, em um ônibus da antiga CMTC, na subida da Rua Augusta, rumo ao centro da cidade de São Paulo, ainda nos tempos da Faculdade de Arquitetura da USP (FAU - USP), em um caderno de anotações. A música foi gravada pela primeira vez em 1983 como tema da novela Dancin Days. Disponível em http://pt.wikipedia.org/wiki/Guilherme Arantes.
} 
O que nos resta dizer depois da sabedoria presente nestes versos? São versos que professam a fé no amanhã, o sonho realizado, a superação da injustiça e de todas as divisões, a participação de cada homem e de cada mulher na história. O tempo final é de paz, amor, justiça, fraternidade universal e isso tudo para louvar ao Criador.

O povo não esconde seu sofrimento. Ao contrário, sinaliza sua presença para torná-lo consciência, luta, mas também conquista. Os direitos fundamentais se unem aos anseios por realização plena, e tudo é assumido no dia de graça. O compositor encontra dentro da realidade as sementes que irão germinar felicidade. Não se aliena e nem para na desesperança. Ao contrário, afirma a vida que nasce das mãos que trabalham em cada palmo de chão. A esperança brota da terra e, por isso mesmo, tensiona a história no dinamismo pascal.

O ser humano aparece nesta composição como ser histórico, consciente de suas possibilidades e limitações e aberto ao dinamismo do amor de Deus. Encontra resistência, mas percebe os sinais já presentes da fidelidade amorosa que orienta o agir humano e suas escolhas fundamentais. Não se sente só, não se sabe só. Caminha em relação com a proximidade de Deus, com a grande família humana e com o universo. Harmoniza os dados do passado com o agir presente e a esperança futura. Não como uma equação lógica, mas como mistério complexo e tecido no plano amoroso de Deus.

\section{Concluindo...}

Desejamos, com esse trabalho, trazer o tema da Esperança para o nosso dia a dia. $\mathrm{Na}$ verdade, um convite a repensarmos o sentido da existência e seu direcionamento.

A esperança nos diz que não somos condenados eternamente a relações desumanizantes, a dificuldades internas pessoais e inter-relacionais, mas que somos abraçados por um Deus Pai que nos torna irmãos e irmãs, que estamos unidos a todo o universo em uma dinâmica de integração profunda. Este é o ideal que está inscrito nas potencialidades do já vivido, do já experimentado, do que é estruturado na história da humanidade e aberto à libertação integral. É a esperança que desperta uma atitude concreta diante de si mesmo, das pessoas, do mundo, da natureza. Uma atitude de disponibilidade e de empenho, pois que se tem adiante um horizonte alargado, para além das racionalidades e dos projetos, dos limites temporais e espaciais, um horizonte carregado de um sentido simbólico, portador de uma mensagem e de um mistério.

\section{Para refletir:}

- A esperança que nasce da experiência de fé mobiliza a pessoa, revoluciona e orienta seu agir cotidiano. Como perceber essa esperança mobilizadora no cotidiano da vida pessoal, dos grupos de convivência, de nosso povo? 
- Enquanto força mobilizadora a esperança pode ser alimentada ou desnutrida? Poderíamos identificar situações de nutrição e de desnutrição da esperança? 